effects of the lathyrus sativus on both man and animals, and states that "horses and bullocks suffer from enteritis as the result of its use, and others lose control over the hind limbs, becoming paralysed."

The lathyrus aphacus is poisonous; the seeds are narcotic and produce intense headache.

Lindley considers the leguminosæ taken as a whole a poisonous order, and that "those species used for food by man or animals are exceptions to the general rule, the deleterious juices of the order not being in such instances sufficiently concentrated to prove injurious, and being replaced to a considerable extent by either starch or sugar."

F did not observe any stiffness or loss of power in the hind limbs of the horses I saw; the action of the poison appeared to be confined to the respiratory centre or the nerves of respiration, and then only when the animal was called upon to exert himself. Prof. Robertson's opinion appears to be a logical one, as death from asphyxia is likely to follow division of the recurrent laryngeal nerves. Different animals appear to be affected in different ways. It would be interesting and instructive to isolate the alkaloid or alkaloids contained in these different seeds and experiment upon animals with them. Horses are fond of this food and do well upon it, and $\mathrm{Mr}$ Malcolm informs me that the Corporation horses in Birmingham receive 3 or 4 lbs. per diem mixed with other corn etc. with satisfactory results, but the precaution is taken to thoroughly cleanse the seeds and afterwards to dry them in a kiln before being used. Without this previous preparation there can be no doubt it is highly dangerous when given in large quantities or when continued too long a time.

\title{
ANGIOMATA FROM THE MENINGES OF THE BRAIN.
}

By Vet.-Capt. C. Rutherford, F.R.C.V.S., Aldershot.

As the microscopical appearances of neoplasms removed from the cranial cavity of the horse are seldom recorded in English veterinary literature, perhaps a short description of the following may not be out of place.

Two tumours found on post-mortem examination in the lateral ventricles of a horse of the $5^{\text {th }}$ Dragoon Guards were kindly given to me by Mr Butler, A.V.D., for examination. A short history of the case is recorded by that officer in the quarterly Journal of Comparative Pathology at page 67 , vol. v. I 892, under the heading "Facial Paralysis with marked Paraplegia," and in which the post-mortem is recorded as follows: "Small tumours of the plexus choroides of each lateral ventricle and also on the lateral parts of the cerebellum." I presume the other organs were healthy, as no mention is made of any other change.

The changes from the normal were most marked: the plexus choroides, in place of resembling thin red cords held in a delicate though firm membrane, were much dilated, red, fungous-like, tortuous and soft, and each plexus presented a tuberous enlargement about its middle, the size of a pea or small bean, and shaded off at the margin. The tumours were non-encapsuled, somewhat nodulated, and 
though firm to the touch were easily cut into, presenting on section a very vascular surface but no hæmorrhage. The tortuous, red, fungouslike appearance of those portions of the plexus choroides which did not actually compose the tumour was most marked, and a great contrast to the firm and somewhat pale ncoplasm.

The tumours were embedded in paraffin, cut, and subsequently treated with chloroform.

Under the microscope the tumour was scen to be composed of pre-existent and newly-formed blood-vessels held in a basis-tissue composed largely of young connective tissue. The blood-vessels were full of blood and more or less dilated in a sacculated and spherical manner, and being tortuous formed wide abrupt cavities more or less separated by the young connective tissue noted. The wall of the smaller vessels was composed of an cndothelial layer, and external to that a single layer of cubical epithelioid cells (see Plate IV.). In the firmer or older portions of the neoplasms the tissue-basis was plentiful and wellformed, and held the blood-vessels wide apart, whilst in the younger parts it was of much more recent formation and not nearly so plentiful. In the latter position, i.e., in the more recently formed portions, the blood-vessels, new and old alike, were margined by clusters of leucocytes, and it was to be noted that in these groups there was a marked tendency to the formation of embryonic blood-vessels-the cells were arranged in parallel rows-and even in this stage of their growth the vast majority of the new vessels contained blood. In the plexus choroides adjoining the tumours this formation of new bloodvessels was the marked feature, especially where no young connective tissue had been formed. The farther removed from the free plexus choroides that the neoplasm was examined the greater was the proliferation of the connective-tissue elements; and the thicker and stronger became the walls of the new vessels and the greater their calibre. The walls of the blood-vessels, old or new, did not appear to be implicated in any retrogressive change, such as calcareous deposit, nor was there any thickening of the coats of pre-existent vessels to be noted.

From the above it may fairly be inferred that the development of this angioma was from new granulation tissue, if one may so term the leucocytic exudation noted on the surface of the plexus choroides; new vessels and vascular sinuses having first been formed in that exudate there followed development and gradual condensation of connective tissue between the vessels, until the stage of tumour was reached. The neoplasms were not produced merely by dilatation and cavernous degeneration of blood-vessels.

\section{A FCETAL MONSTROSITY*}

By F. L. Gooch, F.R.C.V.S., Stamford.

ON the 27 th of November last I was called to attend to what proved to be a very peculiar and difficult case of calving. On examination I found that the hinder end of the calf was presenting, the hind fetlocks appearing outside the vulva. I was able to deliver the hind quarters as far as the pelvis, but no farther, nor could I make a satisfactory 